\title{
Learning By Doing Approach In Engineering Graphics Course
}

\author{
Aniket Suryawanshi ${ }^{1}$, Mahesh L. Deshpande ${ }^{2}$ \\ ${ }^{1}$ KES, Rajarambapu Institute of Technology, Rajaramnagar, Affiliated to Shivaji University, Kolhapur, India. \\ ${ }^{2}$ KES, Rajarambapu Institute of Technology, Rajaramnagar, Affiliated to Shivaji University, Kolhapur, India. \\ ${ }^{1}$ aniket.suryawanshi@ritindia.edu \\ ${ }^{2}$ mahesh.deshpande@ ritindia.edu
}

\begin{abstract}
The drawing of visual representations is important for students, at the same time, students have ability to develop model from drawing. In this sense, this paper represents experiences of students in the process of product development. Product development with the perspective of Problem based learning (PBL). Here innovative teaching technique in the form of Problem based learning $(\mathrm{PBL})$ for engineering drawing subject in the first year engineering course is used. Result of that semester shows that, this technique improves motivation and learning capability in the students. The result indicates that student needs with a highly structured Scaffold to achieve the highest learning outcome. While further study could be implemented to change pattern of engineering drawing course design. New course design it could be that lectures reduced or eliminated in favor of more hands-on problem solving encounters.
\end{abstract}

Keywords: Problem based learning, innovative teaching technique, engineering drawing, collaborative learning.

\section{Motivation}

In Twenty-first century skills necessitate the implementation of instruction that allows students to apply course content, take ownership of their learning, use technology meaningfully, and collaborate. Many of researchers observe that the current work environment requires engineers to be global citizens, as well as aspirational, ethical leaders.
All education involves either problem solving or preparation for problem solving. When teachers and academic institutions skip the problem-formulating stagehanding facts and procedures to students without giving them a chance to develop their own questions and investigate by themselves - students may memorize material but will not fully understand or be able to use it.

\section{INTRODUCTION}

Problem-based learning (PBL) provides a structure for discovery that helps students internalize learning and leads to greater comprehension. Problem-Based Learning (PBL) is where students work in small groups to explore a specially-designed problem under the guidance of an instructor. They observe that such collaborative learning environments hold promise but most experiments with these methods have been carried out on a one-shot basis: an author tries a new method in a course...many students respond well to the new method; and most of them never see anything like it again.

This paper represents how drawing subject can teach in engineering education in more effective way using students centered approach. The author applied product development or development of model from drawing, this new concept of interaction with students and teach during whole semester in his subject. The author was written conclusions based on results obtained from final results of the class on which this technique was applied with the ones where classical method of teaching used. 
Problem-Based Learning (PBL) is a teaching method in which complex real-world problems are used as the vehicle to promote student learning of concepts and principles as opposed to direct presentation of facts and concepts. In addition to course content, PBL can promote the development of critical thinking skills, problem-solving abilities, and communication skills. It can also provide opportunities for working in groups, finding and evaluating research materials, and life-long learning.

Any subject area can be adapted to PBL with a little creativity. While the core problems will vary among disciplines, there are some characteristics of good PBL problems that transcend fields.

The problem must motivate students to seek out a deeper understanding of concepts.

The problem should require students to make reasoned decisions and to defend them.

The problem should incorporate the content objectives in such a way as to connect it to previous courses/knowledge.

If used for a group project, the problem needs a level of complexity to ensure that the students must work together to solve it.

If used for a multistage project, the initial steps of the problem should be open-ended and engaging to draw students into the problem.

\section{IMPLEMENTATION OF TECHNIQUE}

The construction of physical models is a key step for the project-based learning. Main stage of the project phases is the construction of model and prototype. The author was implemented this activity in 10 weeks. Author made plan of 10 weeks for students to complete this activity. Plan of activity for students was used by author. This is the activity where every student knows about what they have to be learned in engineering drawing subject. Also what they have to do in whole semester.

Week 01: Problem findings- This the first step where students search the problems in society related to their subject. Most of them find commercial problems also. Here as a facilitators or teacher's role is very important.

Week 02: Group Formation- In this step facilitator asked students to make groups in heterogeneous manner. Heterogeneous in gender-wise, in leadership quality-wise, in communication skills-wise, in these sense students made groups of themselves.

Week 03: Problem Allotment- In this step facilitator or teacher allotted them proper problem based on course syllabus and considering probable completion time.

Week 04: Individual Solutions- Facilitator asked students to come up with individual solution on paper as well as in Auto CAD. Students has to complete drawing of that solution with help of drafting software (Auto CAD).

Week 05: Peer Assessment and Suggestions from facilitator - Here every individual discussed his/ her solutions with teammates. After peer reviewed in group discussion, students know the proper solution or direction and started work accordingly. Here facilitator given suggestions to groups.

Week 06: Searching of Resources - To complete model or prototype every group needs required wooden baton as per dimensions. At their individual level student searched all the tools and wood as per requirement.

Week 07: Preparation Product (Stage-I) - Students started their work in institutes workshop. In first stage students cut the wood as per required dimensions.

Week 08: Preparation Product (Stage-II) - In this stage students did specific operations on wooden job. At the end students pasted or modelled complete geometry.

Week 09: Report writing- In this stage student started to write report on their activity. Students completed report and power point presentation in MS- Office.

Week 10: Oral Assessment- In this week students presented their work to facilitator.

\section{Procedure Of Assessment Of Technique}

1. Articulation of the learning outcomes of the project. What students to know or be able to do as a result of participating in the assignment? 
2. Creation of the problems, this will be an actual situation that resembles something students may encounter in their future careers or lives.

3. Establishment of the ground rules at the beginning to prepare students to work effectively in groups.

4. Introduction to students to group processes and take warm up exercises to allow them to practice assessing both their own work.

5. Students take on different roles or divide up the work up amongst themselves.

6. Information about basics and advancement of the subject.

7. Establishment of the rubrics that how you will evaluate and assess the assignment.

\section{Photographs Of ONe OF The Model}

\section{MAKING CONDUCTED ACTIVITY}

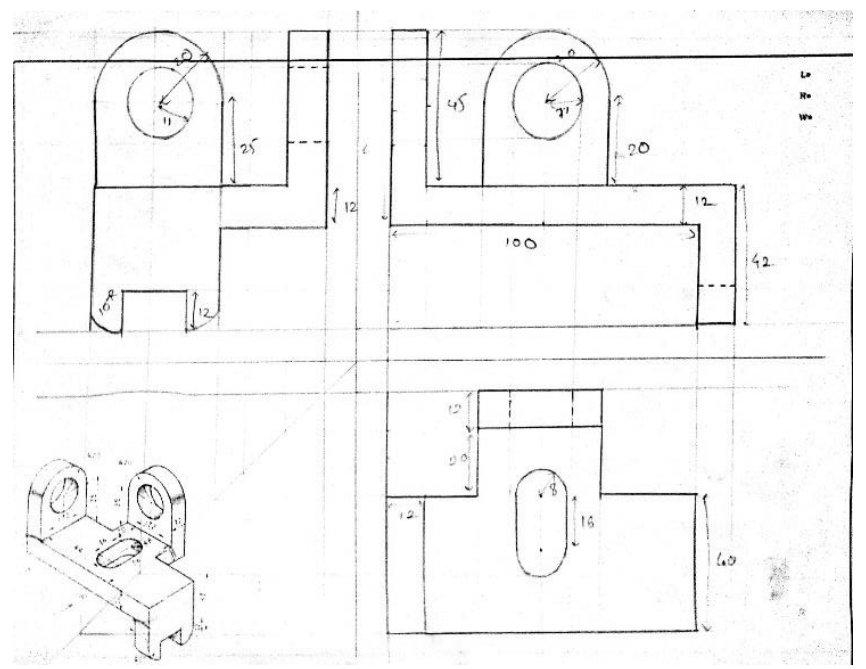

PHOTOGRAPH 01: PHOTOGRAPH OF GRID BOOK DRAWING

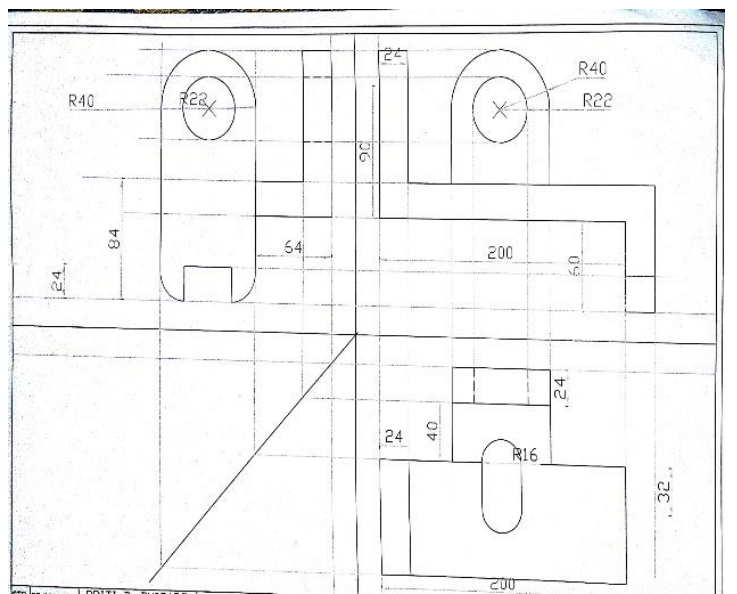

Photograph 02: Photograph Of Auto CAd Drawing

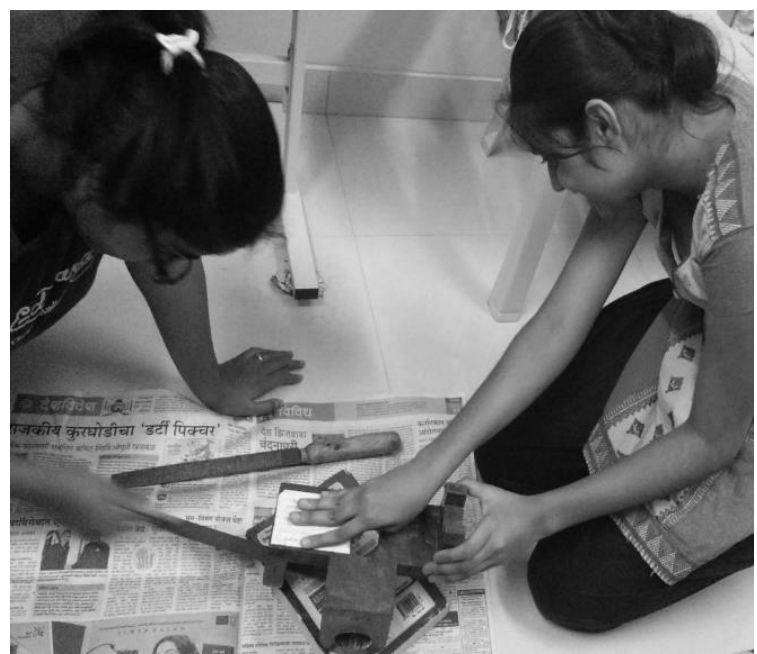

Photograph 03: Cutting Process

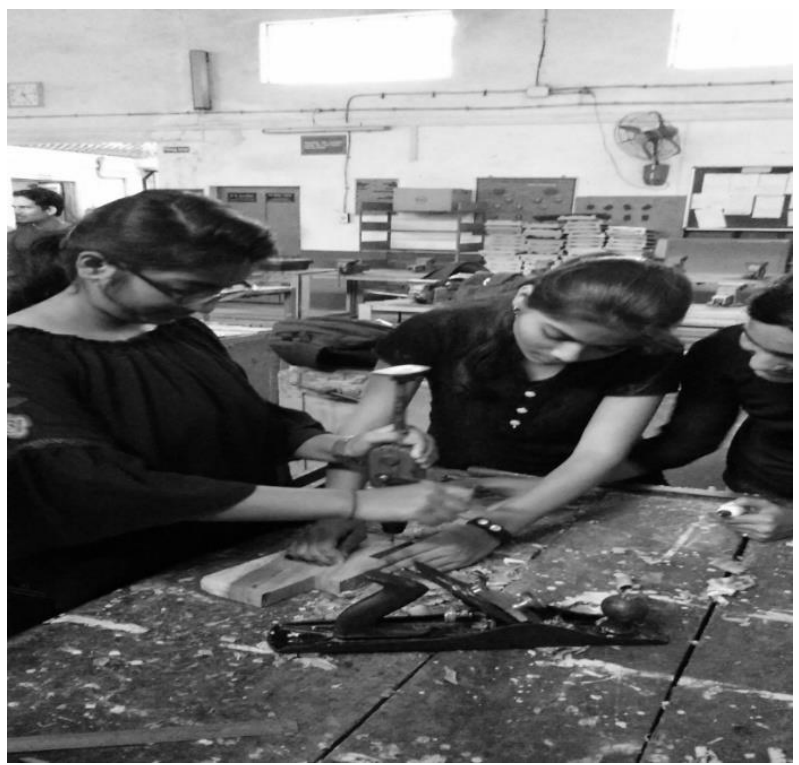

Photograph 04: MANUfacturing Process 


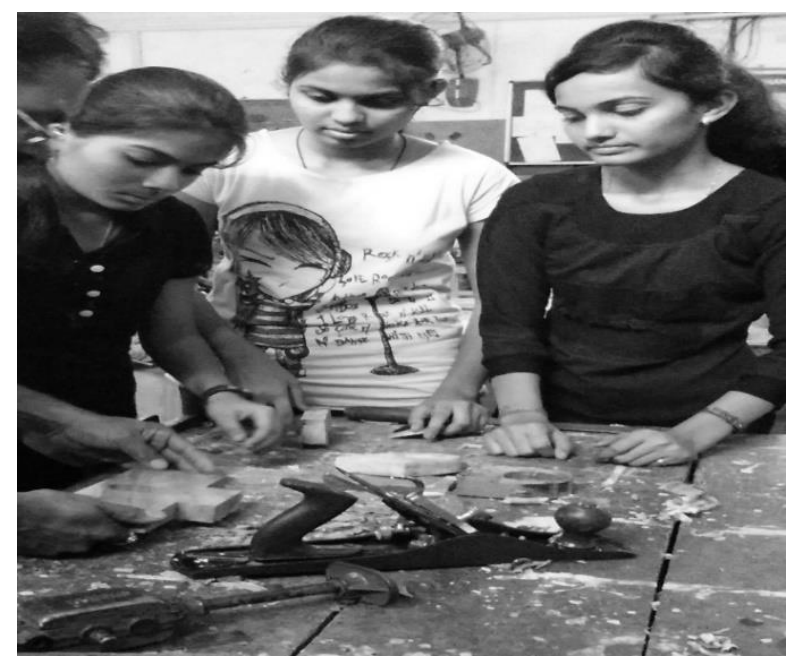

PHOTOGRAPH 05: JOINING PROCESS

\section{FRONT VIEW}

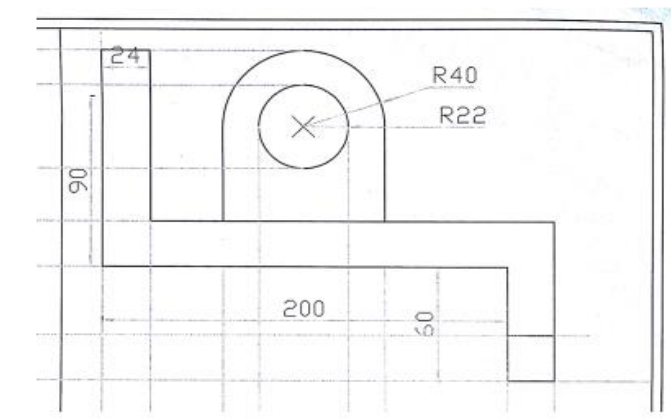

Photograph 06: Auto CAd Drawing Of Front VieW

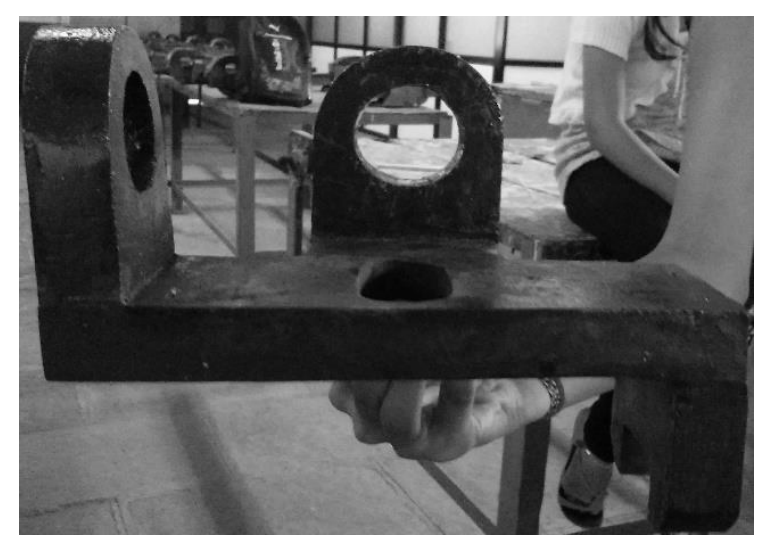

Photograph 07: Front View Of PrePAREd Model

\section{TOP VIEW}

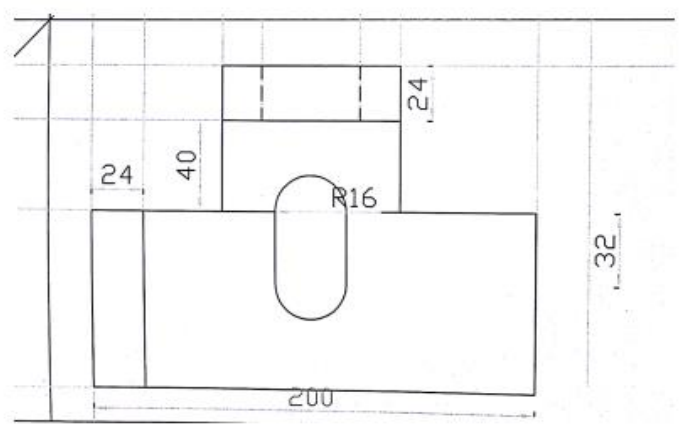

Photograph 08: Auto Cad Drawing Of Top View

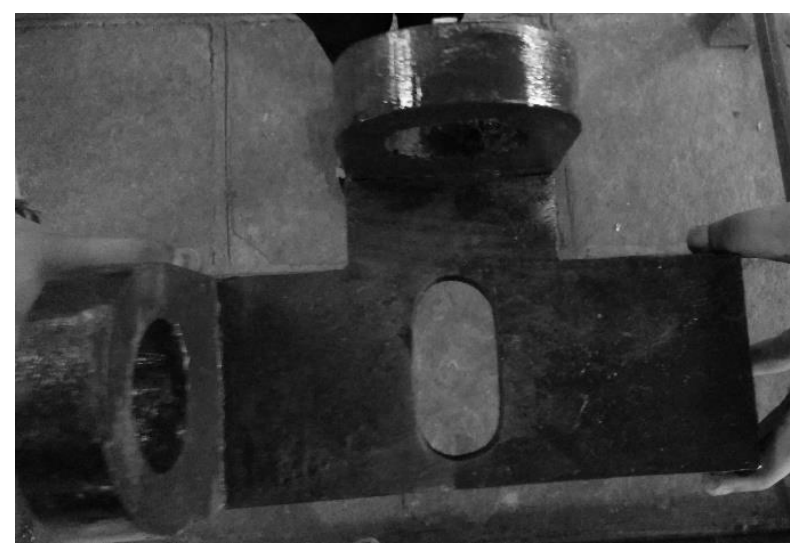

Photograph 09: Top View Of Prepared Model

\section{SIDE VIEW}

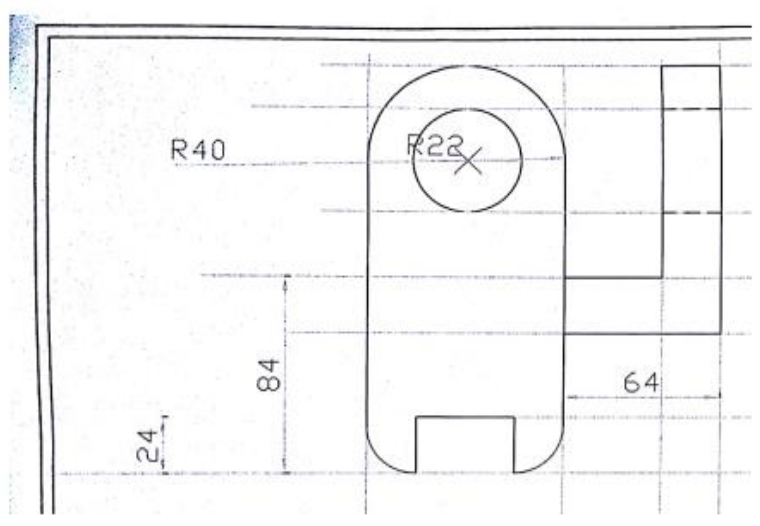

Photograph 10: Auto CAd Drawing Of Side View 


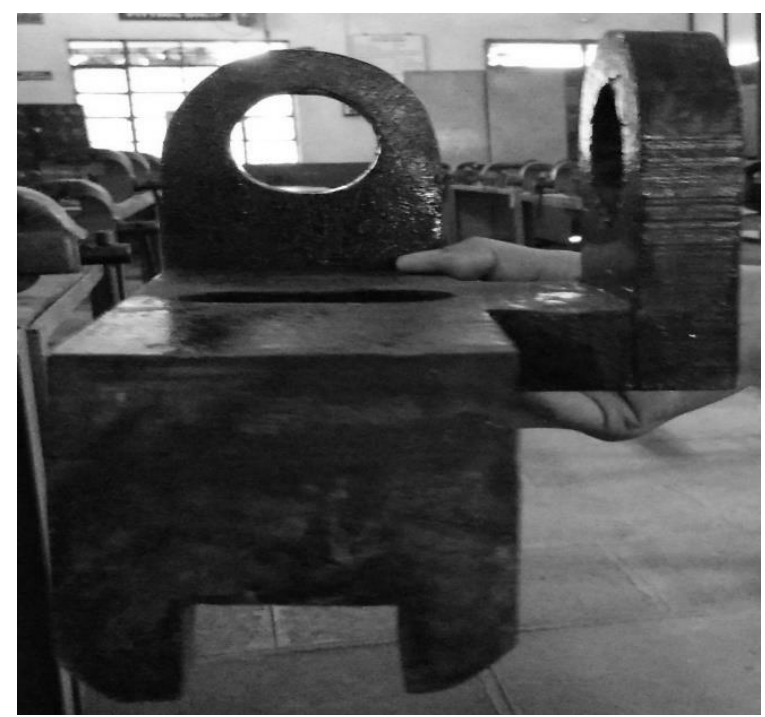

Photograph 11: Side View Of Prepared Model

\section{Suitability OF TechniQue To COURSE}

Engineering drawing course need to relate to the student's expectations, discipline and maintain their interest. The main objectives of the drawing course for teacher is

1) To teach students the main drawing techniques.

2) To enable students to read and transmit the details of drawings into understandable information and instructions;

3) To improve student's visualization skills so that they can apply these skills in developing new products.

4) To construct basic and intermediate geometry considering manufacturing standards and safety majors.

5) To teach students to present their ideas using drawings.

These objectives are very common, so the main innovation in teaching this subject was the introduction of a problem-based learning approach in the progressive assessment.

On the basis of course objectives the learning objectives of the drawing course in which students are able to

LO 01: Understand the importance of basic concepts and principles of engineering drawing.

LO 02: Realize and appreciate the importance of engineering drawings as a medium of communication to convey ideas in engineering fields.

LO 03: Develop and improve the spatial visualization skills, and apply four key principles which are accuracy, speed, neatness, and time management

LO 04: Equip students with basic skills required in engineering drawings,

LO 05: Develop the ability to communicate with others through the language of technical drawing and sketching. And the ability to read and interpret engineering drawings created by others.

\section{DIFFICULTIES FACED IN IMPLEMENTATION IN FIRST YEAR COURSE}

Ways of improving the experience of first year undergraduate students at university is a topic of discussion and research at universities across the globe. A number of issues that academic staff need to be aware of when they teach first year students have been identified as a result of these discussions and research. These include:

- Students often finding first year confusing and isolating until they have learned to manage and navigate their way through the challenging new learning environment posed by university.

- First year students didn't know about practices which have to be follow in workshops.

- Diversity of backgrounds and the range of experience that students have when they enter institute.

- A conflict of expectations between teacher and students regarding knowledge students bring to institute.

\section{RESULTS AND DISCUSSION}

Feedback of students revealed that majority of students' agreed to "Problem-based learning" helped them create interest, better understanding \& promotes self-directed subject learning. Students had scored average grades in conventional assignment (Class participation) is $\mathbf{2 . 6 9}$, but after PBL students scored average grades in Moodle Quiz is 3.29. Quiz was based on basic concepts of Engineering 
Drawing. Significant improvement in overall performance observed. The first year experience has a significant impact on academic success, perseverance and student retention

PBL assignments can be short, or they can be more involved and take a whole semester. PBL is often group oriented activity, so it is beneficial to set aside classroom time to prepare students to work in groups and to allow them to engage in their PBL project.

\section{Conclusions}

Substantial improvement in the post-test scores clearly reveals acceptance of PBL over conventional learning. There is evidence that PBL is popular with its students, associated with better problem-solving skills, that it promotes lifelong learning skills and probably does not sacrifice important areas of knowledge. However, it needs additional resources compared with traditional approaches. This paper uses the authors' experiences in implementing these techniques. In particular, those activities developed in the Department of Automobile Engineering, Rajarambapu Institute of Technology, Rajaramnagar, Maharashtra (India) since 2017

\section{ACKNOWLEDGEMENT}

I am grateful to the support and information received from various sources to complete this activity. I on behalf of students highly grateful towards workshop superintendent (Prof. M. L. Deshpande) and their staff during the product preparation. Sincerely thanks to Mr. M. S. Kumbhar \& Mr. Waghmare who helped students a lot.

\section{REFERENCES}

[1] Dochy, F., Segers, M., Van den Bossche, P., \& Gijbels, D. (2003). Effects of problem-based learning: A metaanalysis. Learning and instruction, 13(5), pp. 533-568.

[2] Jonassen, D. H., \& Hung, W. (2008). All problems are not equal: Implications for problem-based learning. Interdisciplinary Journal of Problem-Based Learning, 2(2), 4.
[3] Onyon, C. (2012). Problem-based learning: A review of the educational and psychological theory. The clinical teacher 9(1), pp. 22-26.

\section{Photographs of The Model Making Conducted}

\section{Activity}
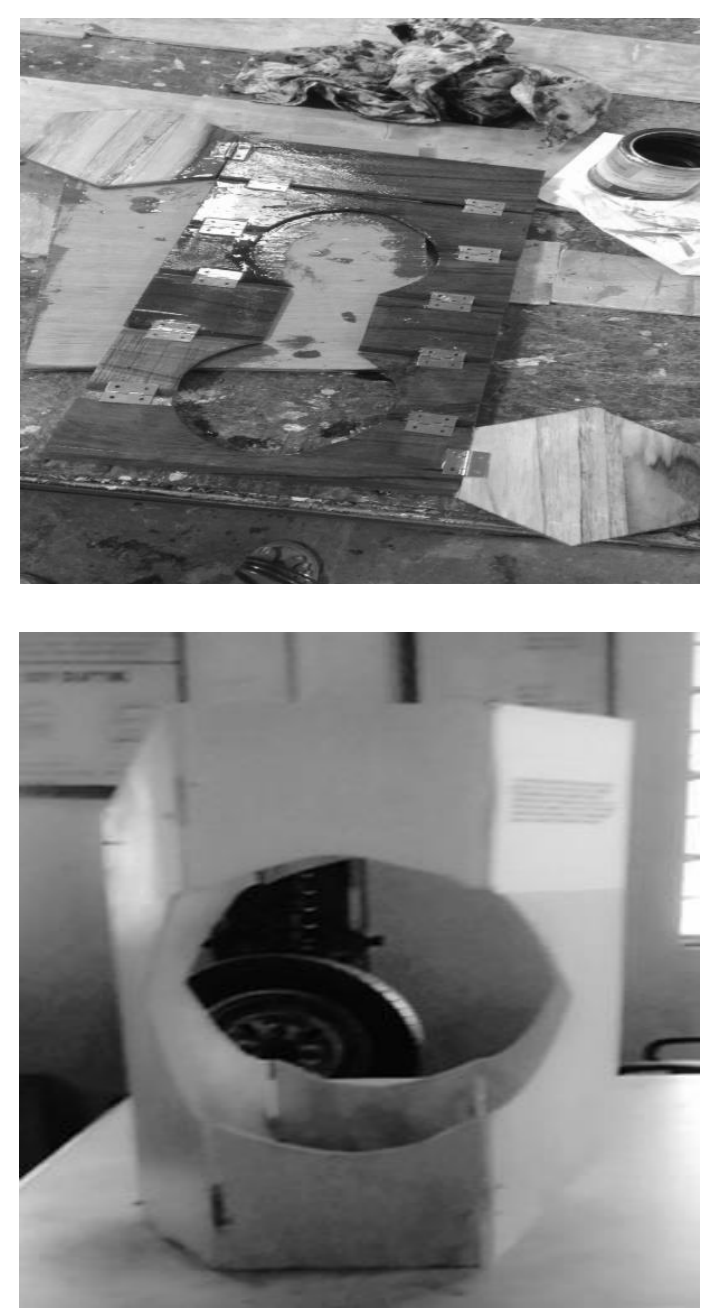

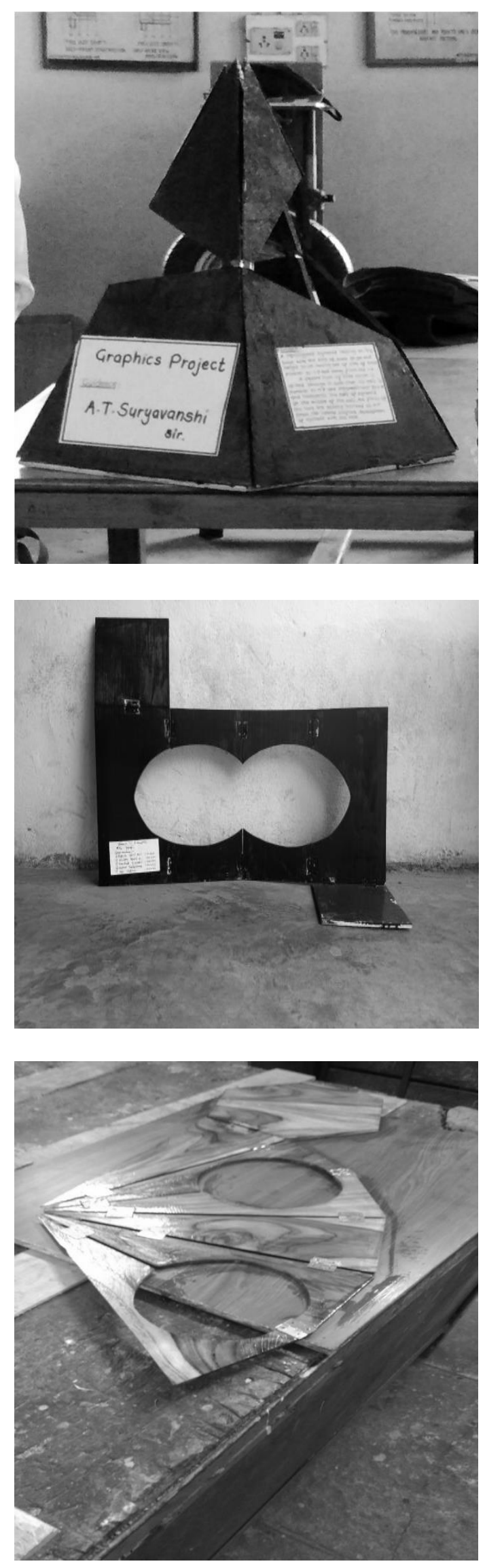